\title{
A place and time for humor: leader humor in Confucian cultures
}

\author{
Inju Yang ${ }^{1}$ (D) and Chu-Chen Rosa Yeh ${ }^{2}$ \\ ${ }^{1}$ Management, College of Business and Law, RMIT University, 124 La Trobe Street, Melbourne VIC 3000, Australia and \\ ${ }^{2}$ Graduate Institute of International Human Resource Development, National Taiwan Normal University, 162, Sect. 1, \\ Heping E. Rd., Taipei, Taiwan, ROC \\ Author for correspondence: Chu-Chen Rosa Yeh, E-mail: rosayeh@ntnu.edu.tw
}

(Received 26 February 2020; revised 21 April 2021; accepted 27 May 2021; first published online 29 June 2021)

\begin{abstract}
Humor has been positively perceived in general. However, research has shown that a leader should adopt humor with care and only after considering the relevant context, such as cultural differences. This study was undertaken to gain insight into how leader humor is perceived in the predominantly Confucian culture of Taiwan, through a series of in-depth interviews with individuals from throughout the hierarchies of various organizations. Overall, our participants expressed conflicting attitudes toward leader humor in the workplace, depending on the place and time of their leader humor experience. Specifically, leader humor was deemed more effective in informal domains and when a good leaderfollower relationship exists. The findings echo the implicit theory of leadership and highlight the need to consider the context when exercising leader humor in Confucian cultures. Implications and future study directions are discussed.
\end{abstract}

Key words: Confucianism; informal domain; humor; leadership; Taiwan

\section{Introduction}

In light of the growing interest in positive work environments (Anderson, Potocnik, \& Zhou, 2014), humor has been recognized as a valuable tool for leaders (Karakowsky, Podolsky, \& Elangovan, 2019; Kong, Cooper, \& Sosik, 2019) because of its capacity to cultivate a range of positive outcomes in the workplace. As an effective and inexpensive motivational tool, leaders are encouraged by many scholars to adopt humor to foster positive workplace emotions or a fun atmosphere (Luthans, Avolio, Avey, \& Norman, 2007; Robert \& Wilbanks, 2012). However, research on leader humor indicates that the effects of leader humor are not straightforward; thus, an organization must carefully consider whether its benefits outweigh its risks (Kong, Cooper, \& Sosik, 2019; Lee, 2015; Neves \& Karagonlar, 2020). In addition, other scholars claim that the context in which leader humor is employed is of paramount importance to its successful use. Considerations in this regard include followers' need for structure (Pundt \& Venz, 2017) and the quality and length of the relationship between a leader and their subordinates (Lee, 2015; Robert, Dunne, \& Iun, 2016).

Another area of active scholarly debate is whether some specific form of leadership is universally applicable across cultures or whether leadership is culturally specific (Lee, Scandura, \& Sharif, 2014; Resick, Martin, Keating, Dickson, Kwan, \& Peng, 2011). Studies have indicated that although certain models of leadership may have appeal regardless of culture (e.g., the charismatic leadership style in the GLOBE study; House, Hanges, Javidan, Dorfman, \& Gupta, 
2004), the implementation of these models may need to vary across cultures to be successful (e.g., leader behavior that enables individual success vs. leader behavior that enables group harmony; see House et al., 2004; Resick et al., 2011). Similarly, culture is a crucial contextual factor that influences the appreciation of certain behaviors (Chang, 2017; Yang \& Li, 2017). For example, in some East Asian countries where Confucianism is the dominant cultural paradigm, seriousness is valued over lightheartedness; thus, humor may not be appreciated in the workplace (Hsieh, Hsiao, Liu, \& Chang, 2005; Yang, Horak, \& Chi, 2020).

Although quantitative research has indicated leader humor has a positive influence on employee outcomes in Confucian cultures (e.g., Ko, 2018; Lee, 2015; Mao, Chiang, Zhang, \& Gao, 2017), adopting a qualitative methodology to uncover the nuances of how leader humor is perceived can shed more light on how certain contextual factors give rise to different perceptions of leader behaviors. By conducting an exploratory study with in-depth interviews, this study aimed to obtain important insights into how context influences the appreciation of leader humor among individuals in Confucian cultures.

This study was conducted in Taiwan, which has a value system rooted in Confucianism. The findings of this study, which are derived from interviews with 17 individuals from different hierarchy levels of various Taiwanese organizations, indicate that although humor is generally appreciated, concerns about the appropriate practice of leader humor is also apparent. The key determinants of responsiveness to humor were found to be the level of focus on task vs. relationship, the interacting parties, and whether humor was employed in a formal domain or an informal domain. Overall, participants expressed conflicting attitudes toward the use of leader humor across formal and informal domains, which suggests that leaders must take context into consideration when applying various principles and behaviors.

This study contributes to the literature on leadership and cross-cultural management. First, by adopting in-depth interviews, this study uncovered how individuals perceive leader humor and why their attitudes - positive or negative - may differ. This study thus extends the literature on the importance of context in leadership and the use of humor (Kong, Cooper, \& Sosik, 2019). Even when engaging in seemingly positive behaviors, leaders must be conscientious about appropriately deploying behaviors such as using humor. Second, the in-depth interviews about leader behaviors conducted in this study offer practical and realistic insights into cross-cultural leadership. Although a principle of leadership may be normative (e.g., the value of charisma), appropriate leader behavior (e.g., leader humor) can vary depending on culture (Yang, Kitchen, \& Bacouel-Jentjens, 2017). By investigating leader humor in Taiwan, this study also responds to the call for additional leadership studies outside Western contexts (Tsui, Nifadhar, \& Ou, 2007). Finally, the contrasting attitudes toward leader humor expressed by the participants in this study highlight the necessity of considering the informal domain to gain a holistic understanding of leadership. This finding builds on the body of literature suggesting that the formal and informal domains are complementary and integrated in Confucianism-dominant Asian management (Yang, 2006, 2015, 2016).

The remainder of this paper is structured as follows. In the first part of this paper, we briefly discuss cultural context and leadership. A brief introduction to leader humor is then provided, followed by the research questions. The second part of this paper includes the methodology and findings of the study. The implications of this research and future study directions are also presented.

\section{Literature review}

\section{Context and leadership}

Many leadership theories have spread globally and become common concepts for managers and executives in corporations worldwide (see Eisenbeiß \& Brodbeck, 2014; Takahashi, Ishikawa, \& Kanai, 2012). These theories tend to reflect North American cultures with high individualism 
(IND) and low power distance (PD) and mostly adopt the private sector perspective (Eisenbeiß \& Brodbeck, 2014). For example, transformational leaders are suggested to have a relatively close relationship with their followers and to encourage their followers to participate in the management process (Smith \& Peterson, 1988), which is in line with cultures with low PD (Hofstede, 1983). However, such transformational leadership with participative leader behavior may not work well in a culture with high PD.

Researchers have long recognized the influence of national culture on leadership attributes and effectiveness (Dorfman, Javidan, Hanges, Dastmalchian, \& House, 2012). Some argued that although the idea of leadership may be similar, its behavioral manifestations may vary across cultural settings (House et al., 2004; Resick et al., 2011). Accordingly, Vandenberg and Lance (2000) advised researchers to establish measurement equivalence in their questionnaires prior to making comparisons across groups, particularly when conducting cross-cultural research. This practice ensures that variables of interest have similar meanings and thus are comparable across cultures (Drasgow \& Kanfer, 1985; Yeh, Lin, \& Chen, 2014).

While commonalities provide bases for comparing and understanding differences (Alba \& Navarro, 2011), contextualization is particularly useful for researchers seeking to understand culturally embedded constructs (Lam, Huang, \& Lau, 2012). For example, although trust in leaders has been demonstrated to be important to followers across cultures, a stark contrast can be observed between the neutrality principle in the West and the affective bond in China (Miao, Newman, Schwarz, \& Xu, 2013). Similarly, despite the fact that nearly all cultures value superior morality and ethics in their leaders (Brown \& Treviño, 2006), the ethical appropriateness of whistle-blowing tends to differ across cultures (Waytz, Dungan, \& Young, 2013). Paternalistic leadership theory is a good example to demonstrate the importance of culture in leadership. Paternalistic leadership has three distinctive characteristics: authoritarianism, benevolence, and morality (Farh \& Cheng, 2000), which are more commonly exhibited by leaders from Confucian cultures with low IND and high PD.

People from one culture may use their own cultural value system as an absolute standard (Resick et al., 2011). Culture plays a major role in the specific content of leadership prototypes (Den Hartog et al., 1999), and implicit leadership theory suggests that leader effectiveness is dependent on the expectations of subordinates for leader prototypes (Foti \& Lord, 1987). Given the research gaps in the aforementioned topics, additional empirical research is essential for examining how certain leader behaviors, such as leader humor, are endorsed and valued in the Confucian cultural context.

\section{Context and leader humor}

In general, humor contributes to group productivity because of its positive effects on group cohesiveness, communication, and creativity. Moreover, humor has been associated with less turnover and absenteeism (Robert \& Wilbanks, 2012). Leader humor refers to the extent to which a leader uses humor with subordinates (Cooper, Kong, \& Crossley, 2018) and is thought to influence subordinates positively (Karakowsky, Podolsky, \& Elangovan, 2019; Ko, 2018; Lee, 2015; Mao et al., 2017) and be an effective tool for managing emotions within groups (Romero \& Pescosolido, 2008). Therefore, humor is often cited as a key interpersonal resource for leaders to have (Cooper, Kong, \& Crossley, 2018; Gkorezis, Hatzithomas, \& Petridou, 2011).

Despite an overall positive picture of leader humor presented by many scholars, its successful use may be challenging (Cooper, Kong, \& Crossley, 2018). A growing body of research has focused on the complexity of leader humor. Some have claimed that the effectiveness of humor depends largely on the content of the humor - whether positive or negative (Lee, 2015; Neves \& Karagonlar, 2020); however, others have argued that the perception of leader humor is influenced by the quality of pre-existing relationships - for instance, whether subordinates have trust in the leader (Lee, 2015). The characteristics of the interacting parties, such as the 
gender of the leader (Decker \& Rotondo, 2001) or the tenure of the subordinates (Robert, Dunne, \& Iun, 2016), also influence the effectiveness of leader humor. Many studies have underscored the necessity of a leader applying humor with care in consideration of its appropriateness to a given context (Karakowsky, Podolsky, \& Elangovan, 2019; Kong, Cooper, \& Sosik, 2019; Lee, 2015; Neves \& Karagonlar, 2020; Taecharungroj \& Nueangjamnong, 2015).

Humor is culture-bound (see Kong, Cooper, \& Sosik, 2019). In the West, individuals who have a sense of humor are positively perceived as being more extroverted, which is a socially desirable trait. By contrast, those who lack a sense of humor tend to be negatively perceived (Cann \& Calhoun, 2001; Priest \& Swain, 2002). Moreover, subordinates tend to view humorous supervisors as motivating, confident, friendly, intelligent, and pleasant leaders (Priest \& Swain, 2002). Westerners tend to regard the use of humor as a common social tactic and evidence of a positive disposition, whereas the Chinese tend to regard the use of humor as a special behavior particular to humorists (Yue, Jiang, Lu, \& Hiranandani, 2016). Research indicates that humor in Confucian cultures tends to differ from Western humor because it tends to be subtle and more delicate; thus, in Confucian cultures, humor is more likely to elicit a thoughtful smile (i.e., a smile that signifies that the interacting parties are on the same wavelength) than hilarious laughter (i.e., belly laughter; Yue, 2010). Confucianism teaches the virtues of emotional restraint and subtleness and how these virtues can positively affect psychological health and preserve interpersonal harmony. Those from Confucian cultures assume the existence of a continuous social order that requires them to constrain their behaviors or acts - this attitude applies to expressing their emotions in the workplace (Lam \& O'Higgins, 2012). Accordingly, the expression of positive and negative emotions is less obvious in Confucian-influenced collectivistic cultures than in individualistic cultures (Eid \& Diener, 2001). Humor is used in a latent and suppressed manner because of the Confucian emphasis on observing appropriate etiquette during social interactions (Hsieh et al., 2005).

According to Confucius, 'If a person is not serious, he is not respected' (Liao \& Chang, 2006: 10). Moreover, humor has been equated with intellectual shallowness and social informality (Xu, 2011); thus, respectable individuals in a Confucian society must restrain from laughter to demonstrate dignity and social formality (Xu, 2011; Yue, 2010). Past research has presented empirical evidence that showed humor being devalued under Confucianism (Yue, 2010). For example, in a study conducted by Rudowicz and Yue (2003) in the Confucian society of China, humor failed in ranking as a characteristic of an ideal Chinese personality. Jiang, Yue, and Lu (2011) also found that Chinese undergraduates tended to associate humor with unpleasant adjectives and seriousness with pleasant adjectives, with the opposite being true for American undergraduates. Given the more restrained sense of humor in those from Confucian cultures, an investigation into those from such a culture can illuminate how cultural context influences the effectiveness of leader humor.

\section{Method}

We set the theoretical framework and questions in advance to guide our exploration into the topic of leader humor and to structure our findings. Following the principle of grounded theory (Glaser \& Strauss, 1967), we began by setting a broad objective for our investigation of leader humor. Subsequently, after extensive data analysis, we developed an interest in contrasting the reception of leader humor in the formal and informal domains. As these specific areas of interest emerged, we returned to the literature for guidance. This movement between our data and the literature helped in the development of our research questions and constituted the starting point for the development of our theory (Edmondson \& McManus, 2007).

\section{Research question}

Our guiding research question was how is leader humor appreciated in the workplace in a Confucian culture? Aspects of this question included the definition and perception of humor, 
which helped inform our understanding of leader humor. Other aspects of this question were the benefits of, concerns with, and appropriate occasions for leader humor. By probing these interrelated questions, we collected data to construct an emergent model that illustrates various levels of emphasis on leader humor in distinctive organizational contexts in formal and informal domains.

\section{Research setting and participants}

A qualitative approach was adopted in this study to explore leader humor in the Taiwanese workplace. In-depth interviews were conducted with eight leaders and nine followers (a total of 17 interviewees). The leaders and the followers were not from the same company; thus, the collected data were not reciprocal between the participants. The number of interviews was determined by reaching thematic saturation (Guest, Bunce, \& Johnson, 2006). Each interview, which took 40-60 min, was based on a set of questions that pertained to perspectives on humor and leader humor at work. An interview guide with probe questions was followed, and the interviews were conducted in Taiwanese Mandarin (the mother tongue of the participants). During and after the interviews, the participants were reminded that the data would only be used for academic purposes, that full confidentiality was guaranteed, and that the names of participants would be removed from the interview data. The interviews were audio-recorded, and field notes were taken.

The participants were corporate managers and employees who were contacted through purposive sampling of people with substantial experience of being a leader or follower across hierarchies and industries. The research team started their search for participants who met the sampling criteria in their professional networks and also asked identified participants to recommend further qualified participants in their professional networks. Having both leaders and followers as participants allowed us to collect a balanced set of views reflecting the reality of leadership (Kong, Cooper, \& Sosik, 2019). Although managers cannot automatically be assumed to be leaders (Mintzberg, 1998) and leadership differs at an organizational level and a team or dyad level (Kong, Cooper, \& Sosik, 2019), we determined that managers with experience in leading a team of subordinates would be appropriate participants for our study (see Kong, Cooper, and Sosik, 2019) given our interest in leader humor in daily interactions.

Managers with over a year of experience in their current job were thus selected under the assumption that these managers were familiar with and fully qualified in leading their subordinates. The managers were mostly from the middle-south region of Taiwan, were between the ages of 26 and 62 years, had a tenure of 1-25 years, and led a team of 3-80 people. By contrast, the followers were mostly from the north, were between the ages of 24 and 40 years, and had a tenure of 3 weeks to 4 years. The participants were employed by various organizations from industries such as service, manufacturing, telecom, education, logistics, and optoelectronics. Information on the participants is presented in Table 1 .

\section{Analysis of the interview data}

The audio-recorded interviews were transcribed verbatim and then translated into English. Content analysis was conducted to identify themes from the transcript. We followed the process outlined by Groggins and Ryan (2013) for capturing data fragments from the transcript, forming provisional categories, consolidating data at an abstract level, and determining how categories related to one another. Provisional categories (e.g., the definition of humor and frequency of leader humor) were created on the basis of the research questions, and data fragments were classified into these categories.

During the process of translation, the second author and her graduate research assistant, who are native Mandarin speakers, discussed back and forth the initial provisional categorizations. Once the translation and provisional categorization were completed, the first and second authors re-examined the data to consolidate and determine each category while engaging in another iteration of literature review. After further discussion, the provisional categories were divided into 
Table 1. Information on the interviewees

\begin{tabular}{|c|c|c|c|c|c|c|c|}
\hline $\begin{array}{l}\text { Leader/ } \\
\text { follower }\end{array}$ & Gender & Age & Tenure & Position & $\begin{array}{c}\text { Number of } \\
\text { subordinates/ } \\
\text { team members }\end{array}$ & Unit & Industry \\
\hline Leader 1 & Male & 36 & 6 years & Senior manager & 15 & Enterprise research center & Service (corporate consultant) \\
\hline Leader 2 & Female & 53 & 7 years & Section manager & 20 & Research and innovation department & Manufacturing (hardware furniture) \\
\hline Leader 3 & Female & 50 & 18 years & Manager & 3 & Personnel section & Manufacturing (textile) \\
\hline Leader 4 & Male & 56 & 25 years & Owner & 30 & - & Service (restaurant) \\
\hline Leader 5 & Male & 49 & 3 years & District manager & 80 & Business department & Service (insurance) \\
\hline Leader 6 & Male & 62 & 6 years & Supervisor & 7 & Information and technology section & Communication \\
\hline Leader 7 & Male & 50 & 6 years & Director & 51 & Logistics and warehouse center & Service (medical supply logistics) \\
\hline Leader 8 & Male & 26 & 1 year & Program coordinator & 33 & Conference project & Education (university) \\
\hline Follower 1 & Female & 26 & 1 year & Intern & 7 & HR department & Manufacturing (glue) \\
\hline Follower 2 & Female & 25 & 1 year & English teacher & 5 & Tutor & Education (language center) \\
\hline Follower 3 & Female & 25 & 6 months & Intern & 14 & Planning department & Optoelectronic (solar energy) \\
\hline Follower 4 & Female & 24 & 3 weeks & Intern & 5 & HR department & Manufacture (computer) \\
\hline Follower 5 & Female & 25 & 3 years & Club member & 20 & Pop dance club & Education (university) \\
\hline Follower 6 & Female & 25 & 1 year & Intern & 7 & HR department & Service (corporate consultant) \\
\hline Follower 7 & Male & 31 & 4 years & Employee & 12 & Enterprise research center & Service (corporate consultant) \\
\hline Follower 8 & Male & 27 & 1 year & English teacher & 5 & Tutor & Education (language center) \\
\hline Follower 9 & Female & 40 & 6 months & Team member & 2 & Project team & Education (university) \\
\hline
\end{tabular}


First-order Analysis

Definition of humor
Quote: "Humor depends on the relationship that you have
with those who share humor."
Quote: "We use the word 'empathy' instead of 'humor'."
Natural or nurtured?
Quote: "It takes time to develop a sense of humor."
Frequencies and timing
Quote: "It occurs occasionally (not often)."
Quote: "Need to understand everybody's personality. After
knowing each other, one does not make mistakes with humor."

\section{Necessary at work?}

Quote: "Humor could ease tension at work."

Quote: "Humor is not helpful all the time at work for tasks and performance."

Quote: "It depends on the culture of an organization."

Right occasions (situations)

Quote: "If the situations is not right, then it would be

inappropriate... It would be rude in some formal situations."

Quote: "Humor could be used in dinner parties although it

may occur during a meeting at work."

Quote: "It is o.k. to use humor in private."

Figure 1. Contextual appreciation of humor in Confucian cultures.

additional categories. To document the reasoning process, effort was exerted in comprehensively describing the categories. The final step of the analysis involved making sense of the data by drawing figures to demonstrate how the data fit together.

In line with our interest in determining how leader humor in day-to-day interactions illustrates leader behaviors within a team, the unit of analysis was the interactions between a leader and a team of subordinates at the dyad or team level. Figure 1 shows the progression of the first-order analysis, which led to emergent themes concerning the contextual appreciation of leader humor, especially the clear distinction between the appropriate use of humor in the formal and informal domains. As indicated in Figure 1, we grouped the characteristics of humor described by our participants when they were asked to define humor, whether humor is natural or nurtured, and the frequency or timing of leader humor. We then assembled the characteristics according to the perceptions of the respondents (left box in Figure 1) and applied an appropriate label (e.g., first entry, left box in Figure 1: 'Definition of humor'). The next step was to compare the data and develop a list of higher-order analytic dimensions (Van Maanen, 1988) complete with descriptors that would facilitate theoretical analysis (e.g., middle box in Figure 1: 'Humor depends on relationships and requires caution'). Finally, we used data displays (see Miles \& Huberman, 1994) to create general emergent themes (e.g., right box in Figure 1: 'Humor is contextual'), which are useful for constructing an emergent theoretical model.

For presenting the results, we numbered our interviewees and provided information regarding their roles in organization hierarchies to indicate precisely where particular information was derived from. The quotes were labeled according to the following notations: Le-1 (Leader 1) and Fo-1 (Follower 1).

\section{Findings}

The research question of this study was how is leader humor appreciated in the workplace? This research question encompassed the functions of leader humor at work and was developed from our expectation that the perceptions and understanding of humor would reveal the attitudes of people toward humor. Contextual factors, such as relationship and time, emerged as key aspects 
of humor appreciation in our analysis. Therefore, our research question yielded insights into reservations about the use of leader humor due to its other-oriented nature, which requires time and relationship building, and also structured our investigation into the role of leader humor with regard to why and how leader humor may be used at work. Figure 1 describes the results obtained for the aforementioned research question from the first-order analysis to the emergent theme.

\section{How is humor defined?}

The majority of the participants had an outcome-driven view of humor because they highlighted that 'humor makes people happy and makes the atmosphere harmonious' (Le-8, Fo-3, Fo-4, Fo-6, and Fo-8). Some respondents defined humor according to its characteristics, suggesting that 'humor is about making fun of oneself (Le-6), or in terms of process, suggesting that humor is about 'viewing a thing from different perspectives' (Fo-9). However, participants also opined that 'humor is not so evident' (Le-7) and that humor may be 'an ability that cannot be quantified or measured' (Fo-1). Humor was perceived to be complicated, and participants suggested that 'using humor in a standardized way is impossible' (Le-3) given that 'a fine line exists between being humorous and being insensitive' (Fo-5).

Moreover, perspectives on humor depended on recipients and the quality of relationships 'with those who share humor' (Le-3), thus 'the same words [in humor attempts] mean different things to different people' (Le-5). In a similar vein, some respondents preferred to be more subtle about humor, suggesting that 'we do not use the word 'humor.' We call it 'empathy.' Empathy can help smooth the communication process. With empathy, one can adjust behaviors' (Le-2). One interviewee suggested that 'humor implicates wisdom' (Fo-2), and another opined that humor reflects 'wisdom from one's accumulated experience and educational background' (Le-3). Therefore, for a good leader to be communicative and to create a good work environment, being empathic rather than humorous is what matters. Overall, humor was not defined primarily by its characteristics per se but rather by how the humor is appreciated by others, which depends on the relationship between the user of humor and the hearer(s). Leader humor depends on how it is received by followers, not the contents of the humor.

\section{Natural or nurtured?}

More than half of the followers considered themselves to not be particularly humorous. They commented that 'I am not humorous' (Le-2 and Le-6) or 'I am a practical person and I am not good at humor' (Le-3). Most leaders acknowledged that 'humor is not something that one is born with but is something that one needs to develop gradually' (Le-5 and Le-6). They added that 'developing humor takes time' (Le-5) and 'humor is learned from accumulated experiences' (Le-2 and Le-8). Furthermore, some leaders argued that 'humor skills are difficult to improve through intentional learning' (Le-1 and Le-3) because 'humor skills and leadership styles cannot be easily changed or learned' (Le-1). The followers echoed these views, opining that 'only a few techniques of humor can be learned' (Fo-3 and Fo-6). Although 'humor is learned from interacting with people' (Fo-2), 'one cannot intentionally improve their humor ability' (Fo-1 and Fo-7). Such an understanding of humor skills (i.e., it can be nurtured, but with considerable difficulty) indicates the perceived challenges and possible reservations in adopting humor in the workplace.

\section{Frequency and timing of leader humor}

Leader humor is not used frequently, which may reflect the seriousness of Taiwanese culture. Expectedly, some leaders commented that 'I do not use humor frequently' (Le-2, Le-3, Le-5, and Le-6). They attributed the reluctance to use humor in the workplace to organizational and national cultures because 'we are very practical; humor needs to fit in the workplace' (Le-5) 
and 'leaders are not expected to use humor at work in Taiwan' (Fo-3). The concerns of many leaders centered on how and whether leader humor would be appreciated. Comments in this regard concerned hesitancy before engaging in leader humor, for instance, 'I have to think about whether employees will understand my meaning before I say something humorous' (Le-2), and confirmation of being understood after using humor, for example, '[I must] check with a subordinate whether they understood my humor' (Le-3). Such concerns stem from the reality that 'one never knows how others think about me. I always tell myself to be cautious to avoid misunderstandings' (Le-4) and 'some people do not appreciate jokes' (Le-7). Some leaders disparaged the inauthentic use of humor. One leader said, 'humor on purpose will be [perceived as] fake and cannot achieve its effect' (Le-1). Some leaders were overall more concerned that 'humor should be used with caution' (Le-3).

Many claimed that time is required for leader humor to be appreciated, which highlights the importance of context because 'everyone should already get along with one another first' (Le-6) for humor to be positively perceived. Accordingly, the duration of the relationship between leaders and followers appeared to be critical for leader humor. One leader noted, 'there is not much humor when we are still trying to get to know one another; it takes time' (Le-5). Being aware of context, including the personalities and values of others, was suggested as being crucial for successful leader humor, as indicated by the following comment: 'When people understand each other, they know that you are not using humor with bad intentions' (Le-6). The importance of having a good relationship prior to effective leader humor was echoed by a follower in the following comment: 'For newcomers, understanding humor can be difficult, which may result in a feeling of being left out' (Fo-4). Thus, time and relationship development appear to be critical for leader humor to be appreciated by subordinates. Consequently, although leaders may be hesitant to use humor and leader humor may only be used on rare occasions at the beginning of the leader-member relationship, successful leader humor can be adopted after the leader and the followers have spent sufficient time getting to know one another and have established a relationship.

\section{Necessary at work?}

Leaders generally agreed on the benefits of leader humor, which they suggested included the following: (1) fostering a positive working environment, for example, 'using humorous expressions to relax the atmosphere' (Le-1 and Le-7) and 'relieve some intense situations' (Le-2, Le-3, Le-5, and Le-8); (2) motivating employees, as 'people may feel less stress with it [humor]' (Le-3 and Le-7) and humor may help in 'recovering from failures' (Le-5); (3) decreasing social distance, as 'humor shortens the distance between people' (Le-2, Le-3, and Le-7); (4) building relationships, as 'humor allows for building a partnership, which leads to a better result' (Le-1 and Le-7); and (5) facilitating smoother communication, given that 'humor in the workplace is a lubricant for communication' (Le-1, Le-7) and 'with leader humor, employees can openly share their views' (Le-2). Furthermore, 'humor can be used to express one's opinions in a less awkward way' (Le-2, Le-3, Le-5, and Le-8). The perceived functions of leader humor are similar to those identified by studies in the West, where leader humor is appreciated and perceived positively.

Despite the appreciation of leader humor, the answer to whether leader humor is necessary at work is complicated. Many leaders considered humor to be incompatible with serious tasks. Some interviewees commented that 'humor can be an effective leadership tool, but it is not a necessity. Humor is not helpful all the time at work for tasks and performance' (Le-6) and that 'humor does not enhance work efficiency per se' (Le-3). This belief may be more apparent in certain organizations because the appreciation of leader humor 'depends on the units or organizations that one belongs to, chiefly whether the enterprise values the importance of humor. Some enterprises are more disciplined and restricted, prohibiting humorous interactions and behaviors' (Le-8).

Subordinates also expressed some uncertainty about the necessity of leader humor. Many followers appreciated the possible functions of leader humor to 'reduce pressure' (Fo-5), 'make the 
environment more relaxed, and build relationships with employees' (Fo-3, Fo-7, and Fo-8). Nonetheless, leader humor was considered to be more an expression of wisdom. One subordinate stated, 'one needs to put aside their superiority so that they can get along well with their subordinates' (Fo-2). Furthermore, some followers argued that 'a leader has to be serious and humorous. If the leader combines the two, then it will be a lot better, even though it is not applicable in every situation' (Fo-7 and Fo-8). However, they also added that 'being humorous is not part of a leader's job. Although a leader is supposed to make everybody feel at ease while at work, this responsibility does not mean that they must use humor' (Fo-1).

Overall, although leader humor was appreciated as an effective leadership tool, this trait was not considered necessary per se due to possible conflicts with task performance. However, when the views of leaders and followers were compared, followers appeared to appreciate leader humor more when they understood leader humor to be related to wisdom or behaviors that resulted in a better work environment for them.

\section{Suitable occasions for leader humor}

When concerns regarding leader humor were analyzed in depth, a comment was made that 'everything is a double-edged sword' (Le-6). In this vein, functions of leader humor that were considered beneficial were also regarded as possible disadvantages, particularly the aspect of lightness, which may reduce social distance. Moreover, concerns were raised that leader humor leads 'some people to equate being humorous as not being serious (at work)' (Le-5) and 'if humor is not handled well, as in the case where one does not know when to be serious or humorous, people may misunderstand what one is trying to communicate' (Le-3, Le-5, Le-7, and Le-8). Moreover, participants argued that 'leader humor may be negative if it is used too often or overtly' (Le-7); therefore, 'one cannot depend on humor too much for management. It makes the subordinates become disorderly' (Le-4). Leader humor in a low-performing team was considered to be particularly inappropriate because it 'signifies that the leader does not care and is indifferent to the team' (Le-1).

A healthy distance between a leader and their followers may also be jeopardized by leader humor because 'once you are in a leadership position, the pressure level increases. I could say whatever I wanted in the past, but I cannot do it now because things are different' (Le-5). Leader humor may cause subordinates to cross the line at work because if they get too close with a supervisor, they may consider them a friend rather than a supervisor' (Fo-4). Yet, leader humor can also result in 'a distance between each other' (Le- 2) when it becomes 'similar to bullying because lots of humor turns out to be personal attacks' (Fo-5, Fo-6, Fo-7, and Fo-9).

The aforementioned concerns regarding leader humor can be resolved by considering the role of informal settings, where leader humor may be more highly appreciated. Crucially, 'the use of humor depends on people, time, and situations' (Le-3), and failure to consider these factors 'would make the use of humor counterproductive at work' (Le-3). In particular, respondents distinguished the appropriateness of humor on the basis of whether humor is used in a formal or informal setting, as indicated by the following comment: 'Humor could be rude in some formal situations, and it would be harmful for a leader to use it and create more negativity' (Le-2). Another participant opined that 'it's fine to use humor in private, but one needs to be careful with it in a formal situation' (Le-7). In an informal setting, such as at lunches, dinners, or workshops outside the company, 'people may be quite talkative about gossip, movies, or happenings inside and outside of the company' (Fo-4), and 'people hang out together for midnight snacks or something, and my manager make lots of jokes about food' (Fo-7).

Overall, although leader humor is generally appreciated, it is perceived to be out of place and considered a distraction in the domain of task-focused formal interactions. Therefore, leader humor is suggested to be more appropriate in an informal domain than in a formal one because these domains entail different foci and leader behaviors, with formal domains being more focused 
Figure 2. Leader behaviors with different levels of focus in various organizational contexts in Confucian cultures.

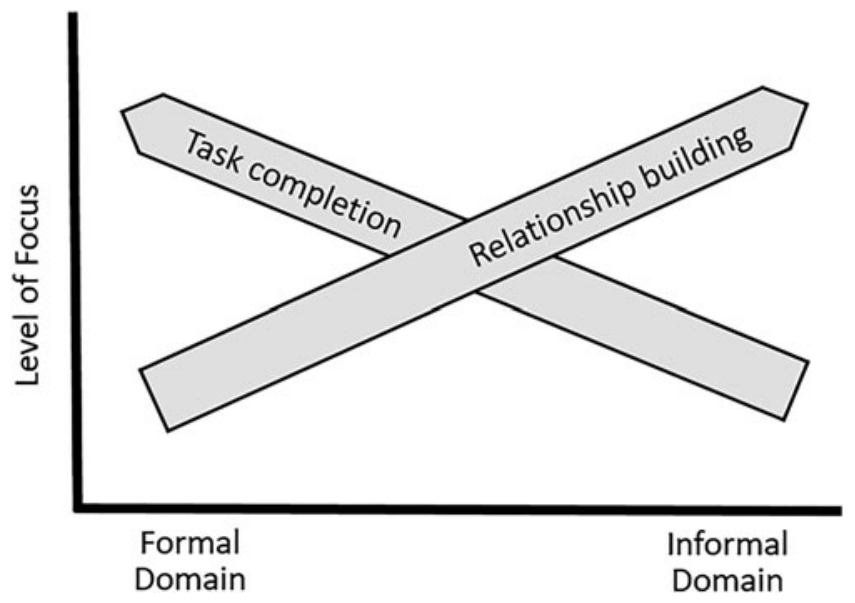

on serious tasks and informal domains being focused on relationship building, in which humor may have a role. Figure 2 illustrates the crossover of leadership between formal and informal domains in Taiwan.

\section{Summary of the research findings}

Although studies have considered the content or intentions of leader humor to define what humor is (Robert \& Wilbanks, 2012), the findings of the current study from Taiwan indicate that leader humor should be defined on the basis of how it is received in the workplace. Accordingly, context, such as leader-follower relationships and whether the situation is formal or informal, is a key factor in determining why and how leader humor is appreciated. For example, leader humor is more effective later in a relationship than at the outset. When relationships have been established and a leader and their followers know each other well, leader humor becomes less vulnerable to possible misunderstanding. Moreover, leader humor can be understood in a broader sense that encompasses empathy, wisdom, and small talk about private affairs at work.

The benefits and disadvantages of leader humor are two sides of the same coin. Although leader humor may be appreciated when used to build positive relationships in informal domains to accomplish smooth communication and positive motivation, in formal domains, leader humor may be distracting and reduce social distance, both of which are problematic. These tensions and challenges in the use of leader humor can be resolved by clearly delineating formal and informal domains and knowing in which one humor may have a place. Formal and informal domains are complementary and equally important; however, leaders must remember to focus more on task performance in the formal domain and harmony and relationship building in the informal domain. Therefore, compared with the formal domain, the informal domain offers a greater opportunity for leader humor to be appreciated when employed to reinforce relationship building. Table 2 presents the overall summary of the findings of this study.

\section{Discussion}

The context-dependent appreciation of leader humor and the importance of relationships in the effectiveness of leader humor found in this study reflect the high collectivism and low individualism of the Confucian cultures of many East Asian countries (Triandis, 1995). Strong collectivistic cultures support harmony with others, which causes an individual to be intensely aware of 
Table 2. Summary of findings about leader humor in Confucian cultures

\begin{tabular}{ll}
\hline $\begin{array}{c}\text { Definition of } \\
\text { humor }\end{array}$ & $\begin{array}{c}\text { Humor makes people happy and makes the atmosphere harmonious which depends on how } \\
\text { it is appreciated by others, which further depends on relationships with and/or the } \\
\text { personality of recipients; some see it as empathy and wisdom }\end{array}$ \\
$\begin{array}{c}\text { Natural or } \\
\text { nurtured? }\end{array}$ & Humor is nurtured from interactions with others \\
$\begin{array}{c}\text { Frequencies, time } \\
\begin{array}{c}\text { Necessary at } \\
\text { work? }\end{array}\end{array} \quad \begin{array}{l}\text { Yes: Positive working environment, reducing social distance, relationship building, smooth } \\
\text { communication }\end{array}$ \\
No: Distractions (not compatible with task), compromising healthy distance \\
Right occasions & Informal domains > formal domains \\
\hline
\end{tabular}

the social presence of other people (i.e., relationalism). Humor is one form of communication; hence, the significance of context in the effectiveness and appropriateness of leader humor found in the current study is in line with the theory of high-context communication in the low-individualism cultures of many East Asian countries (Hall, 1976) such as Korea, Japan and Taiwan, where the Confucian thoughts have a wide influence. By contrast, low-context communication with high individualism dominates in Western countries (Fiske, Kitayama, Markus, \& Nisbett, 1998). In such countries, being humorous or using humor indicates a leader with a positive personality, confidence, and good communication skills (Martin, 2007).

Studies from Western countries support the effectiveness of using leader humor at the beginning of a relationship, and consider one of the main functions of leader humor is to help build a new relationship (Gkorezis, Hatzithomas, \& Petridou, 2011). On the contrary, our study participants in Taiwan considered a good relationship a key condition for leader humor to be successful. This finding contrasts with the Western view and indicates that leader humor becomes more effective later in a relationship rather than at its beginning. This study demonstrated how the Confucian values of Taiwan create a high-context cultural setting in which relationships are paramount. In fact, humor may be interpreted negatively when individuals are unfamiliar with one another because Confucian culture promotes order (seriousness), self-discipline, and a strong work ethic, which may be at odds with the use of humor (see Hsieh et al., 2005). Furthermore, leader humor may be more effective when individuals are familiar with one another; however, contextual information does not increase until later in a relationship (Yang, Horak, \& Chi, 2020). Accordingly, adopting leader humor in the workplace in Taiwan may require a more intricate strategy. This finding is in line with the implicit theory of leadership, which suggests that effective leadership depends on subordinates recognizing a match between expected and actual behaviors of the leader (Foti \& Lord, 1987).

This study indicates how leader humor tends to be perceived in Taiwanese organizational contexts and the reasons for this tendency. Moreover, it highlights an important aspect of Taiwanese leadership - the ability to act appropriately in both the formal and informal domains. Although leader humor may conflict with formal leadership due to its perceived frivolousness and may reduce hierarchical order in a company, it can nevertheless be an extremely useful tool for enhancing informal leadership. Effective leaders may use humor to facilitate a positive relationship with their employees in informal domains. A stark contrast exists between the formal office working environment and the informal atmosphere of after-hours socializing in countries with Confucian cultures. After hours, leaders often behave in a manner inconsistent with their formal role. For example, they may allow themselves to be the target of light ridicule and participate in fun activities (Fang, 2012; Yang, 2006). Although leaders are expected to meet both formal structural (e.g., hierarchy) and informal relational (e.g., harmony in the workplace) demands (Yang \& Horak, 2019; Zhang, Waldman, Han, \& Li, 2015), maintaining a balance between the two can 
be challenging, particularly for foreign managers who are unfamiliar with the complementary coexistence of the formal and informal domains.

The appreciation for and concerns about leader humor found in this study indicate the complex nature of Taiwanese leadership and management, with different foci and emphases across formal and informal domains in an organization. The results of this study support the significance of informal contexts and highlight the necessity of considering the dynamic interrelationships of Confucian values with formal and informal domains in management, which may appear separated but are actually complementary (Yang \& Horak, 2019; Zhang et al., 2015) and connected in a larger system (Fang, 2012).

\section{Conclusions}

This study was undertaken to gain insight into how leader humor is perceived in the predominantly Confucian culture of Taiwan. Through qualitative interviews, we found conflicting attitudes toward leader humor in the workplace, depending on the place and time of our participants' leader humor experience. Specifically, leader humor was deemed more effective in informal domains and when a good leader-follower relationship exists. The findings echo the implicit theory of leadership and highlight the need to consider the context when exercising leader humor in Confucian cultures. This study reveals the roles of relationship and the formal or informal domain in determining the appropriateness and effectiveness of leader humor in Confucian cultures. Contributions and implications of these findings, as well as limitations of the study and future research suggestions are discussed below.

\section{Contributions and implications}

Few studies have examined cross-cultural differences in general humor perceptions (e.g., Jiang, Yue, \& Lu, 2011); thus, this study is one of the first to provide evidence that the appreciation of leader humor is dependent on the context, whether formal or informal. Moreover, this study indicates the importance of scholars examining not only formal domains but also informal domains for understanding organizations in Confucian cultures. This study contributes to the literature on leadership and cross-cultural management. First, through in-depth interviews, this study attempted to answer the why and how questions related to leader humor. We identified a role for leader humor in informal domains of the workplace, which was rarely discussed in the literature (Yang \& Horak, 2019). Thus, this study opens a new research dimension for leadership scholarship. In line with the implicit theory of leadership, this study argues the importance of informal domains as an important context for leaders to consider when using humor in Confucian cultures. By highlighting the role of informal domains, this study cautions against a simplistic adaptation of a particular kind of leader behavior across cultures and contexts.

The contextual variability of the appropriateness of leader humor revealed in this study indicates the necessity of considering the informal domain to gain a holistic understanding of leadership in Confucian cultures. This finding is in line with Yang's $(2006,2015,2016)$ argument that although they may appear disconnected on the surface, formal and informal domains are in fact complementary and integrated in Confucian cultures. Familism (i.e., considering an organization as a family unit) and emotional consideration among individuals are important for people belonging to this culture (see Yang, 2006, 2014, 2015), where communal relations in an informal domain can be instrumental for coping with stress at work by providing necessary social support (Takahashi, Ishikawa, \& Kanai, 2012). Studies that explore the context of the informal domain can contribute to obtaining a holistic view of leadership and management in Confucianismdominant societies (see Yang, 2006, 2015, 2016).

Second, by investigating leader humor in Taiwan, this study contributes to the literature on leadership and cross-cultural management by responding to the call for additional studies on leadership in non-North American settings, given that most theories were developed in the 
USA (Dorfman et al., 2012; Lee, 2015; Lee, Scandura, \& Sharif, 2014; Resick et al., 2011; Tsui, Nifadhar, \& Ou, 2007). Most leadership studies have adopted the North American concepts of leadership, such as transformational leadership and ethical leadership (see Tsui, Nifadhar, \& Ou, 2007; Vandenberg \& Lance, 2000). Although studies that have adopted the normative aspects of leadership, such as the GLOBE study (House et al., 2004), may shed further light on leadership, an investigation into particular leader behavior may yield additional insights into possible crosscultural differences. Thus, even though certain ideas may have a universal appeal and be exhibited across many cultures (e.g., the importance of leader fairness), behavioral manifestations may vary depending on cultural setting (see Miao et al., 2013).

Although examining all leader behaviors may be impossible, studies on representative leader behaviors (e.g., studies on humor and conflict resolution strategies) can generate practical and realistic insights into how cross-cultural leadership should be approached (Yang, Kitchen, \& Bacouel-Jentjens, 2017; Yang \& Li, 2017). For example, although research has argued that leader avoidance, which can be regarded as a form of laissez-faire leadership, is negative (Avolio, Bass, \& Jung, 1999), an empirical study that used a survey in China demonstrated that leader avoidance, in relation to team conflicts, is actually positive (Yang \& Li, 2017). Our study indicated that a seemingly positive leader behavior, such as leader humor, is also appreciated differently depending on the time and context of its occurrence. Such understanding would enhance the intercultural competence of an expatriate manager working in a Confucian culture, allowing them to operate more efficiently and effectively.

\section{Limitations and suggestions for future research}

Despite the aforementioned contributions, we must acknowledge several limitations of this study, which may also represent opportunities for future research. This study examined the role of the informal domain in organizations for better understanding leadership and management in Taiwan. Although the informal domain plays a significant role in building harmonious relationship in the context of low-individualism cultures, differences may exist among social groups or generations (e.g., Generation X vs. millennials) in their attitudes toward and engagement in relationship building. Quantifying the significance of the informal domain is difficult. Nevertheless, additional studies should be conducted on the role of the informal domain in general and also in specific situations (e.g., different contexts).

Although the in-depth interviews on leader behaviors conducted in this study generated practical and realistic insights into cross-cultural leadership, we acknowledge the benefit of future empirical studies that would use additional qualitative or quantitative paradigms. In this study, we recruited participants across hierarchies and companies; however, the purposive sampling technique adopted may have limited the heterogeneity of the participants, possibly resulting in premature thematic saturation. Overall, additional empirical studies on leader humor can help clarify the findings of previous research on humor in organizations, many of which are conceptual (see Cooper, Kong, \& Crossley, 2018; Karakowsky, Podolsky, \& Elangovan, 2019; Kong, Cooper, \& Sosik, 2019). Moreover, although the current study demonstrated how and why a leader should be sensitive to different cultural contexts by examining the appreciation for leader humor, additional empirical research is essential for identifying specific cultural values and practices related to the endorsement and enactment of different leader behaviors.

We also acknowledge that managers are not necessarily leaders per se (Mintzberg, 1998) and that leadership differs at the organizational level and the team or dyad level (Kong, Cooper, \& Sosik, 2019). In this study, we analyzed leadership at the team or dyad level, in line with our interest in day-to-day leader behaviors. At this level, leader behaviors directly influence subordinates' attitudes and behaviors (Neves \& Karagonlar, 2020; Robert, Dunne, \& Iun, 2016). How leader humor is enacted by leaders at the organizational level and how such enactment is perceived should be explored in relation to organizational cultures and trickle-down effects (Decker \& Rotondo, 2001). 
Finally, we note that although we adopted Taiwan as a representative country of Confucian cultures, differences do exist within this cultural cluster (Yang, 2006). Therefore, the research findings can only be generalized to a certain extent to societies that are still under the influence of Confucian teachings. In addition, given the importance of context revealed in this study, additional research should be devoted to different cultural and industrial contexts, for example, how leader humor is perceived in a country with high PD and high IND (e.g., France). As Niwa and Maruno (2010) concluded, humor norms may not only differ across industries or companies but also across cultures.

Acknowledgement. This work was partially supported by the Taiwan Fellowship Program 2016; and Taiwan's Ministry of Science and Technology [MOST 105-2410-H-003-138 -]. The authors would like to acknowledge the effort of Yu-Wen Ko, a graduate research assistant at the second author's department, in data collection and administration for this research. We also appreciate the two anonymous reviewers for their patience and guidance throughout the review and revision process to help us develop a much stronger paper.

\section{References}

Alba, C., \& Navarro, C. (2011). Administrative tradition and reforms in Spain: Adaptation versus innovation. Public Administration, 89(3), 783-800.

Anderson, N., Potocnik, K., \& Zhou, J. (2014). Innovation and creativity in organizations: A state-of-the-science review, prospective commentary, and guiding framework. Journal of Management, 40(5), 1297-1333.

Avolio, B. J., Bass, B. M., \& Jung, D. I. (1999). Re-examining the components of transformational and transactional leadership using the Multifactor Leadership Questionnaire. Journal of Occupational and Organizational Psychology, 72(4), 441-462.

Brown, M. E., \& Treviño, L. K. (2006). Ethical leadership: A review and future directions. Leadership Quarterly, 17(6), 595-616.

Cann, A., \& Calhoun, L. G. (2001). Perceived personality associations with differences in sense of humor: Stereotypes of hypothetical others with high or low senses of humor. Humor: International Journal of Humor Research, 14, 117-130.

Chang, W.-W. (2017). Approaches for Developing Intercultural Competence: An Extended Learning Model With Implications From Cultural Neuroscience. Human Resource Development Review, 16(2), 158-175 .

Cooper, C., Kong, D., \& Crossley, C. (2018). Leader humor as an interpersonal resource: Integrating three theoretical perspectives. Academy of Management Journal, 61(2), 769-796.

Decker, W. H., \& Rotondo, D. M. (2001). Relationships among gender, type of humor, and perceived leader effectiveness. Journal of Managerial Issues, 13(4), 450-465.

Den Hartog, D. N., House, R. J., Hanges, P. J., Ruiz-Quintanilla, S. A., Dorfman, P. W., \& GLOBE Associates (1999). Culture specific and cross-culturally generalizable implicit leadership theories: Are attributes of charismatic/transformational leadership universally endorsed? [Special Issue]. Leadership Quarterly, 10(2), 219-256.

Dorfman, P., Javidan, M., Hanges, P., Dastmalchian, A., \& House, R. (2012). GLOBE: A twenty-year journey into the intriguing world of culture and leadership. Journal of World Business, 47(4), 504-518.

Drasgow, F., \& Kanfer, R. (1985). Equivalence of psychological measurement in heterogeneous populations. Journal of Applied Psychology, 70(4), 662-680.

Edmondson, A., \& McManus, S. (2007). Methodological fit in management field research. Academy of Management Review, 32(4), 1246-1264.

Eid, M., \& Diener, E. (2001). Norms for experiencing emotions in different cultures: Inter-and within-nation differences. Journal of Personality and Social Psychology, 81(5), 869-885.

Eisenbeiß, S. A., \& Brodbeck, F. (2014). Ethical and unethical leadership: A cross-cultural and cross-sectoral analysis. Journal of Business Ethics, 122(2), 343-359.

Fang, T. (2012). Yin Yang: A new perspective on culture. Management and Organization Review, 8(1), 25-50.

Farh, J. L., \& Cheng, B. S. (2000). A cultural analysis of paternalistic leadership in Chinese organizations. In J. T. Li., A. S. Tsui \& E. Weldon (Eds.), Management and organizations in the Chinese context (pp. 84-127). London: Palgrave Macmillan.

Fiske, A., Kitayama, S., Markus, H. R., \& Nisbett, R. E. (1998). The cultural matrix of social psychology. In D. Gilbert, S. Fiske \&. G. Lindzey (Eds.), Handbook of social psychology (Vol. 2, 4th ed., pp. 915-981). New York, NY: McGraw-Hill.

Foti, R. J., \& Lord, R. G. (1987). Prototypes and scripts: The effects of alternative methods of processing information on rating accuracy. Organizational Behavior and Human Decision Processes, 39(3), 318-340.

Gkorezis, P., Hatzithomas, L., \& Petridou, E. (2011). Impact of leader's humor on employees' psychological empowerment: The moderating role of tenure. Journal of Managerial Issues, 23(1), 83-95.

Glaser, B. G., \& Strauss, A. L. (1967). The discovery of Grounded Theory: Strategies for qualitative research. Chicago: Aldine Pub. Co.

Groggins, A., \& Ryan, A. M. (2013). Embracing uniqueness: The underpinnings of a positive climate for diversity. Journal of Occupational and Organizational Psychology, 86(2), 264-282. 
Guest, G., Bunce, A., \& Johnson, L. (2006). How many interviews are enough? An experiment with data saturation and variability. Field Methods, 18(1), 59-82.

Hall, E. T. (1976). Beyond culture. New York: Anchor Press/Double day.

Hofstede, G. (1983). National cultures in four dimensions: A research-based theory of cultural differences among nations. International Studies of Management and Organization, 13(1-2), 46-74.

House, R. J., Hanges, P. J., Javidan, M., Dorfman, P. W., \& Gupta, V. (2004). Culture, leadership, and organizations: The GLOBE study of 62 societies. Thousand Oaks: Sage Publications.

Hsieh, C., Hsiao, Y., Liu, S., \& Chang, C. (2005). Positive psychological measure: Constructing an evaluating the reliability and validity of a Chinese Humor Scale applicable to professional nursing. Journal of Nursing Research, 13(3), 206-214.

Jiang, F., Yue, X. D., \& Lu, S. (2011). Different attitudes towards humor between Chinese and American students: Evidence from the implicit association test. Psychological Report, 109(1), 99-107.

Karakowsky, L., Podolsky, M., \& Elangovan, A. R. (2019). Signaling trustworthiness: The effect of leader humor on feedbackseeking behavior. The Journal of Social Psychology, 160(2), 170-189.

Ko, Y. (2018). Employees' perception of leader's humor style and pleasant climate as moderated by social conformity. Unpublished master's thesis. National Taiwan Normal University, Taiwan.

Kong, D. T., Cooper, C. D., \& Sosik, J. J. (2019). The state of research on leader humor. Organizational Psychology Review, 9(1), 3-40.

Lam, L., Huang, X., \& Lau, D. (2012). Leadership research in Asia: Taking the road less travelled? Asia Pacific Journal of Management, 29(2), 179-192.

Lam, C., \& O’Higgins, E. E. (2012). Enhancing employee outcomes: The interrelated influences of manager's emotional intelligence and leadership style. Asia Pacific Management Review, 18(4), 441-467.

Lee, D. R. (2015). The impact of leader's humor on employees' creativity: The moderating role of trust in leader. Seoul Journal of Business, 21(1), 59-86.

Lee, K., Scandura, T. A., \& Sharif, M. M. (2014). Cultures have consequences: A configural approach to leadership across two cultures. The Leadership Quarterly, 25(4), 692-710.

Liao, C. C., \& Chang, T. C. (2006, July 3-7). Sense of humor: Americans vs. Taiwanese. [Paper presentation]. 18th ISHS Conference, Copenhagen, Denmark. http://web.ncyu.edu.tw/ chaochih/liaochang.pdf

Luthans, F., Avolio, B. J., Avey, J. B., \& Norman, S. M. (2007). Positive psychological capital: Measurement and relationship with performance and satisfaction. Personnel Psychology, 60(3), 541-572.

Mao, J. Y., Chiang, J. T. J., Zhang, Y., \& Gao, M. (2017). Humor as a relationship lubricant: The implications of leader humor on transformational leadership perceptions and team performance. Journal of Leadership \& Organizational Studies, 24(4), 494-506.

Martin, R. A. (2007). The psychology of humor: An integrative approach. Burlington, MA: Elsevier Academic Press.

Miao, Q., Newman, A., Schwarz, G., \& Xu, L. (2013). Participative leadership and the organizational commitment of civil servants in China: The mediating effects of trust in supervisor. British Journal of Management, 24, 76-92.

Miles, M. B., \& Huberman, A. M. (1994). Qualitative data analysis: An expanded sourcebook (2nd ed.). London: Sage.

Mintzberg, H. (1998). Retrospective commentary on the manager's job: Folklore and fact. In Harvard business review on leadership (pp. 29-32). Boston: Harvard Business School Press.

Neves, P., \& Karagonlar, G. (2020). Does leader humor style matter and to whom? Journal of Managerial Psychology, 35(2), $115-128$.

Niwa, S., \& Maruno, S. (2010). Strategic aspects of cultural schema: A key for examining how cultural values are practiced in real-life settings. Journal of Social, Evolutionary, and Cultural Psychology, 4(2), 79-91.

Priest, R. F., \& Swain, J. E. (2002). Humor and its implications for leadership effectiveness. Humor: International Journal of Humor Research, 15, 169-189.

Pundt, A., \& Venz, L. (2017). Personal need for structure as a boundary condition for humor in leadership. Journal of Organizational Behavior, 38(1), 87-107.

Resick, C. J., Martin, G. S., Keating, M. A., Dickson, M. W., Kwan, H. K., \& Peng, C. (2011). What ethical leadership means to me: Asian, American, and European perspectives. Journal of Business Ethics, 101, 435-457.

Robert, C., Dunne, T. C., \& Iun, J. (2016). The impact of leader humor on subordinate job satisfaction: The crucial role of leader-subordinate relationship quality. Group \& Organization Management, 41(3), 375-406.

Robert, C., \& Wilbanks, J. E. (2012). The Wheel Model of Humor: Humor events and affect in organizations. Human Relations, 65(9), 1069-1097.

Romero, E., \& Pescosolido, A. (2008). Humor and group effectiveness. Human Relations, 61(3), 395-418.

Rudowicz, E., \& Yue, X. D. (2003). Compatibility of Chinese and creative personalities. Creativity Research Journal, 14(3), 387-394.

Smith, P. B., \& Peterson, M. (1988). Leadership, organizations, and culture. Beverly Hills, CA: Sage.

Taecharungroj, V., \& Nueangjamnong, P. (2015). Humour 2.0: Styles and types of humour and virality of memes on Facebook. Journal of Creative Communications, 10(3), 288-302. 
Takahashi, K., Ishikawa, J., \& Kanai, T. (2012). Qualitative and quantitative studies of leadership in multinational settings: Meta-analytic and cross-cultural reviews. Journal of World Business, 47(4), 530-538.

Triandis, H. C. (1995). Individualism and collectivism. Boulder, CO: Westview Press.

Tsui, A. S., Nifadhar, S., \& Ou, A. Y. (2007). Cross national, cross cultural organizational behavior research: Advances, gaps and recommendations. Journal of Management, 33(3), 426-478.

Vandenberg, R. J., \& Lance, C. E. (2000). A review and synthesis of the measurement invariance literature: Suggestions, practices, and recommendations for organizational research. Organizational Research Methods, 3(1), 4-69.

Van Maanen, J. (1988). Tales of the field: On writing ethnography. Chicago: The University of Chicago Press.

Waytz, A., Dungan, J., \& Young, L. (2013). The whistle blower's dilemma and the fairness-loyalty trade-off. Journal of Experimental Social Psychology, 49(6), 1027-1033.

$\mathrm{Xu}, \mathrm{W}$. (2011). The classical Confucian concepts of human emotion and proper humour. In J. Chey and J. M. Davis (Eds.), Humour in Chinese life and letters: Classical and traditional approaches (pp. 50-71). Hong Kong: Hong Kong University Press.

Yang, I. (2006). Jeong exchange and collective leadership in Korean organizations. Asia Pacific Journal of Management, 23(3), 283-298.

Yang, C. (2014). Does ethical leadership lead to happy workers? A study on the impact of ethical leadership, subjective well-being, and life happiness in the Chinese culture. Journal of Business Ethics, 123(3), 513-525.

Yang, I. (2015). Cross-cultural perceptions of clan control in Korean multi-national companies: A conceptual investigation of employees' fairness monitoring based on cultural values. The International Journal of Human Resource Management, 8 (26), 1076-1097.

Yang, I. (2016). Lost overseas? The challenges facing Korean transformational leadership in a cross-cultural context. Critical Perspectives on International Business, 12(2), 121-139.

Yang, I., \& Horak, S. (2019). Formal and informal controls in contemporary Korean management. The International Journal of Human Resource Management, 30(22), 3113-3137.

Yang, I., Horak, S., \& Chi, S. (2020). Leader humor effectiveness - The divergent dynamics of leader humor over time in East Asia and North America. Thunderbird International Business Review, 63(3), 383-395.

Yang, I., Kitchen, P., \& Bacouel-Jentjens, S. (2017). How to promote relationship-building leadership at work? A comparative exploration of leader humor behavior between North America and China. The International Journal of Human Resource Management, 28(10), 1454-1474.

Yang, I., \& Li, M. (2017). Can absent leadership be positive in team conflicts? An examination of leaders' avoidance behavior in China. International Journal of Conflict Management, 28(2), 146-165.

Yeh, C. R., Lin, C. Y., \& Chen, S. Y. (2014). From west to east: Adoption of western measurement scales in Taiwan's organizational research. Asia Pacific Management Review, 19(3), 253-271.

Yue, X. D. (2010). Exploration of Chinese humor: Historical review, empirical findings, and critical reflections. Humor: International Journal of Humor Research, 23, 403-420.

Yue, X. D., Jiang, F., Lu, S., \& Hiranandani, N. (2016). To be or not to be humorous? Cross cultural perspectives on humor. Frontiers in Psychology, 7, 1-10.

Zhang, Y., Waldman, D. A., Han, Y. L., \& Li, X. B. (2015). Paradoxical leader behaviors in people management: Antecedents and consequences. Academy of Management Journal, 58(2), 538-566.

Inju Yang, $\mathrm{PhD}$, is a lecturer in management at the RMIT University, Australia. Dr. Yang also has taught in Singapore, France, Ireland, and Swiss. She received her PhD and MBA from the Michael Smurfit School of Business, University College Dublin, Ireland.

Chu-Chen Rosa Yeh, PhD, is an associate professor in the graduate institute of international human resource development at National Taiwan Normal University (NTNU), Taiwan. She received her MA degree from the school of education of the Ohio State University, USA, and her PhD degree from the management school of National Sun-Yat-Sen University, Taiwan.

Cite this article: Yang I, Yeh CR (2023). A place and time for humor: leader humor in Confucian cultures. Journal of Management \& Organization 29, 122-138. https://doi.org/10.1017/jmo.2021.22 